7. Sidell D, Shapiro NL, Bhattacharyya N. Obesity and the risk of chronic rhinosinusitis, allergic rhinitis, and acute otitis media in school-age children. Laryngoscope. 2013;123:2360-2363.

8. Peracchio HL, Henebery KE, Sharafi M, et al. Otitis media exposure associates with dietary preference and adiposity: a community-based observational study of at-risk preschoolers. Physiol Behav. 2012;106:264-271.

9. Seaberg RM, Chadha NK, Hubbard BJ, et al. Chorda tympani nerve function in children: relationship to otitis media and body mass index. Int $J$ Pediatr Otorhinolaryngol. 2010;74:1393-1396.

\section{ASEPTIC MENINGITIS CAUSED BY COXIELLA BURNETII}

\section{Cristóvão Figueiredo, MD, Flora Candeias, MD, and Maria João Brito, MD}

\begin{abstract}
Acute Q fever can have multiple presentations but neurologic involvement is rare. We describe the case of a 16-year-old female with severe headache and aseptic meningitis with acute Coxiella burnetii infection.
\end{abstract}

Key Words: acute Q fever, Coxiella burnetii, meningitis

Accepted for publication September 22, 2015

From the Infectious Diseases Unit, Centro Hospitalar Lisboa Central, Hospital Dona Estefânia, Lisbon, Portugal.

The authors have no funding or conflicts of interest to disclose.

Address for correspondence: Cristóvão Figueiredo, MD, Centro Hospitalar São João, Serviço de Doenças Infecciosas, Alameda Professor Hernâni Monteiro, 4200-319 Porto, Portugal. E-mail: csmfigueiredo@gmail.com

Copyright (C) 2015 Wolters Kluwer Health, Inc. All rights reserved.

DOI: $10.1097 /$ INF.0000000000000935

$\mathrm{Q}$ fever is a zoonosis caused by the obligate intracellular bacterium Coxiella burnetii. Clinical manifestations of acute infection vary greatly; acute meningitis is a possible but rare form of presentation. We report the case of a patient admitted with aseptic meningitis caused by C. burnetii acute infection.

\section{CASE REPORT}

A 16-year-old female presented to the emergency department complaining of severe headaches (mainly retro-orbital) for the previous 6 days, with photophobia and vomiting for 2 days. She was previously healthy, and was vaccinated according to the Portuguese National Health Department recommendations. She denied regular contact with animals, although she used to visit her grandparents in a rural area, where they had 2 dogs.

On physical examination she was slightly pale, and on ophthalmoscopy the papillary edges seemed attenuated on the left eye. The remaining findings were unremarkable. Blood tests were performed, which revealed microcytic and hypochromic anemia ( $\mathrm{Hg} 10.2 \mathrm{~g} / \mathrm{dL})$, no leukocytosis, thrombocytopenia $\left(105 \times 10^{9} / \mathrm{L}\right)$, elevated C-reactive protein $(107 \mathrm{mg} / \mathrm{L})$ and erythrocyte sedimentation rate $(56 \mathrm{~mm} / \mathrm{h})$ and elevated liver enzymes (alanine aminotransferase $105 \mathrm{U} / \mathrm{L}$, alkaline phosphatase $107 \mathrm{U} / \mathrm{L}$ ). The chest roentgenography showed a mild perihilar infiltrate. The cerebral magnetic resonance imaging revealed no indirect signs of intracranial raised pressure or other significant changes, and a lumbar puncture was performed. Clear, transparent cerebrospinal fluid (CSF) was obtained, with 92 cells $/ \mu \mathrm{L}$ (60\% polymorphonuclear), low glucose value $(60 \mathrm{mg} / \mathrm{dL}$, index CSF/serum 0.4) and elevated protein $(66.3 \mathrm{mg} / \mathrm{dL})$. Blood and CSF cultures were obtained, treatment with ceftriaxone and vancomycin was started, and she was admitted with the clinical suspicion of meningitis. She improved after 2 days and completed 8 days of antibiotic therapy. Blood and CSF cultures were sterile. She was re-evaluated after 4 weeks and remained asymptomatic, but the
C. burnetii serology was then known to be positive (phase II IgM $1 / 256$ and $\operatorname{IgG} 1 / 12$; phase I IgM negative and $\operatorname{IgG} 1 / 64$ ). She was again repeatedly questioned for animal exposure, and she eventually recalled attending a traditional open-air market with livestock, when she last visited her grandparents around 2 weeks before the hospital admission. Diagnosis of Q fever was assumed, and she was treated with doxycycline.

\section{DISCUSSION}

Clinical manifestations of acute $\mathrm{Q}$ fever vary greatly. ${ }^{1-5}$ The most common presentations are self-limited flu-like syndrome, prolonged fever, pneumonia or granulomatous hepatitis, ${ }^{1,3,5}$ but several distinct manifestations have been described, such as meningoencephalitis, myocarditis, erythema nodosum, pancreatitis, thyroiditis, haemolytic anaemia, epydidimitis or mediastinal lymphadenopathy. ${ }^{1}$

Bernit et $\mathrm{al}^{2}$ reviewed a series of patients with acute $\mathrm{Q}$ fever and evidence of neurologic involvement, and concluded that the overall prevalence was $2.2 \%$. In their series, severe headache with a meningeal syndrome was the most common clinical manifestation; encephalitis or meningoencephalitis was more common than meningitis alone; and meningitis was usually lymphocytic. In our case, pleocytosis was mainly because of polymorphonuclear cells, but this is a well-known phenomenon in the initial stages of several lymphocytic meningitis, such as viral, spirochetal, mycobacterial or fungal meningitis. In contrast to Bernit et al's ${ }^{2}$ study, Reilly et $\mathrm{al}^{6}$ reported a rate of $22 \%$ regarding neurologic complications in acute $\mathrm{Q}$ fever, which suggests that it may not be so rare.

Doxycycline is the first-line treatment of acute infection, although it has been suggested that fluoroquinolones could be a better option because of better penetration into the CSF. ${ }^{2} \mathrm{Neu}-$ rologic recovery usually occurs regardless of treatment. ${ }^{2}$ Some studies suggest that ceftriaxone might have bacteriostatic activity against some strains of $C$. burnetii, but this is not the preferred treatment. ${ }^{1}$ In this case report, it is impossible to know whether the patient improved as a part of the natural history of the disease or if ceftriaxone had some impact on its clinical course. We decided to treat the patient with doxycycline to prevent evolution for chronic disease.

In conclusion, acute $\mathrm{Q}$ fever can have a multitude of clinical manifestations, and the epidemiologic clue for exposition to C. burnetii is not always obvious. Although it is generally regarded as a rare occurrence, it is important to recognize $C$. burnetii as a cause of acute meningitis because the first-line treatment for this agent is not usually included in the empiric antibiotic coverage used for meningitis, and the evolution for chronic Q fever could have devastating consequences.

\section{REFERENCES}

1. Maurin M, Raoult D. Q fever. Clin Microbiol Rev. 1999;12:518-553.

2. Bernit E, Pouget J, Janbon F, et al. Neurological involvement in acute Q fever: a report of 29 cases and review of the literature. Arch Intern Med. 2002;162:693-700.

3. Marie TJ, Raould D. Coxiella burnetii (Q Fever). In: Bennett JE, Dolin R, Blaser MJ, eds. Mandell, Douglas and Bennett's Principles of Infectious Diseases. 8th ed. Philadelphia, PA: Elsevier Saunders; 2015:2208-2216.

4. Raoult D, Marrie T, Mege J. Natural history and pathophysiology of Q fever. Lancet Infect Dis. 2005;5:219-226.

5. Diagnosis and Management of Q Fever - United States, 2013 Recommendations from $C D C$ and the $Q$ Fevere Working Group. Recommendations and Reports. March 29, 2013/62 (RR03);1-23.

6. Reilly S, Northwood JL, Caul EO. Q fever in Plymouth, 1972-88. A review with particular reference to neurological manifestations. Epidemiol Infect. 1990;105:391-408. 